\title{
Organization and Concept of Intervention of the Chemical Defence Bases in Switzerland
}

\author{
Urs Ludescher*
}

\begin{abstract}
In contrast to radiological risks, which are the responsibility of the federal authorities, the cantons have to deal with chemical risks. In agreement with the chemical defence concept of the Swiss Fire Fighters Association (SFFA) each canton should have a network of chemical defence bases enabling efficient intervention on site within thirty minutes of a chemical accident. Due to the drafting of the 'Ordinance of $27 \mathrm{Feb}-$ ruary 1991 on Protection against Major Accidents' after the disastrous chemical fire in Schweizerhalle on 1 November 1986, it has been possible to reduce the chemical risks in Switzerland considerably. This could be achieved primarily by reduction of the amounts of hazardous materials in the facilities subject to the ordinance, but also by structural measures, the establishment of powerful intervention forces, and intervention planning. The responsibility for the training of chemical defence specialists is divided between the SFFA and the cantons. The SFFA organizes training courses for officers-in-charge for chemical accidents and for instructors for chemical defence; the cantons and the chemical industry in turn are responsible for the basic training of specialists and officers for chemical defence.
\end{abstract}

Keywords: Chemical accidents · Chemical defence concept $\cdot$ Intervention forces .

Swiss Fire Fighters Association · Training requirements

\section{Legal Fundamentals}

In the field of protection against radioactive radiation the production, use, storing, transport, and disposal of radioactive materials is regulated in the 'Ordinance of 30 June 1976 for Radioactive Protection'.

On the other hand the Swiss Federal Government left the regulation of chemical defence from the beginning to the cantons and municipalities. For the protection of the population the 'Concept for a Coordinated AC-Protection' of 19 February 1981 was drafted and approved by the federal government on 19 May 1981. Subsequently the governments of all the cantons accepted the concept by letter. Up to the moment of the creation of the 'Ordinance of 27 February 1991 on Protection against Major Accidents' [1], which was one of the consequences of the catastrophic fire of a ware-

${ }^{*}$ Correspondence: Dr. U. Ludescher

Chemical Consultant of the

Swiss Fire Fighters Association

Blattenrain 9

Postfach 130

$\mathrm{CH}-9050$ Appenzell

Tel.: +41717801082

E-Mail: urs.ludescher@bluewin.ch house containing herbicides, fungicides and pesticides in Schweizerhalle on $1 \mathrm{No}-$ vember 1986, this concept, which was revised and published again on 24 January 1990 as the "Concept Coordinated AC-Protection' [2], was the only legal basis for the formation of an organization for chemical defence in the cantons.

\section{The Chemical Defence Concept of the Swiss Fire Fighters Association}

According to the existing clear legal fundamentals, specialists from the School for Radiation Protection at the Swiss Institute for Atomic Reactor Research, who are responsible for training in radiation protection, developed towards the end of the 1970s the 'Directions for the Radiation Protection for Fire Fighting Service' and a clear concept for the training of intervention forces of the fire brigades in radiation protection.

Thanks to the initiative of the commander of the fire brigade of the chemical company LONZA AG at that time, Rudolf Sandmeier, the first courses for chemical defence were organized on the training ground of LONZAAG in Visp. The point of main effort of those courses, however, was the control of big hydrocarbon fires.

In order to give the cantons a feasible instrument for the planning and realization for chemical defence, in 1983 the Swiss Fire Fighters Association (SFFA) began to draft a chemical defence concept suitable for use in practice. The first version of this concept, presented at an international seminar on hazardous materials for fire fighters in Munich in March 1984, was further improved and refined to be presented to cantonal authorities at a national conference of the SFFA in Bern in June 1985. There are four important cornerstones characterizing this concept:

1. Each canton should have a network of chemical defence bases enabling intervention on site thirty minutes maximum after a chemical accident in areas with considerable chemical risks - i.e. in regions with factories dealing with hazardous materials and in regions with roads and railways transporting large amounts of dangerous goods. This demand is the result of the experience that without intervention within thirty 
minutes after an accident, damage is very often disproportionately large or even irreparable.

2. In the event of a chemical accident not only the responsible chemical defence base has to be called in, but also the nearest local fire brigade and the regional support base unless the latter is identical with the chemical defence base. The main task of the local fire brigade is the rescue of persons and animals in danger as well as the containment of the scene of the accident. The regional support base brings the heavy fire fighting equipment into action whereas the chemical defence base as a rule only turns out with its chemically trained specialists and the required equipment.

3. Every chemical defence base has to bring its resources of staff and equipment into line with the existing chemical risks in the area of intervention. This includes recruiting, training, and integration of an adequate number of qualified chemical consultants to advise the officer-in-charge of the intervention forces in case of a chemical accident. The extent of these resources can be deduced from the possible accident scenarios and the corresponding intervention plans.

4. As the responsibility for the protection of the population against chemical dangers in principle is completely up to the cantons according to the 'Concept Coordinated AC-Protection from 24 January 1990' [2], each canton has to appoint an expert for chemical defence. Among other activities this cantonal expert for chemical defence has the following tasks:

- Issue of directives for the training and further education of the specialists from the chemical defence bases;

- Supervision of the training and intervention planning of the chemical defence bases;

- Recruitment of chemical consultants for the chemical defence bases;

- Regular examination of the chemical defence organization in the canton with regard to staff, equipment and training.

Parallel to the creation of the chemical defence concept the SFFA drafted and published in 1985 'Directives for Chemical Defence for Fire Brigades/Directives for the Training of Chemical Defence Specialists' [3]. In these directives the most important principles for the organization of chemical defence on the federal, cantonal, and regional level have been formulated as well as the main tasks of the chemical defence specialists at the different levels. Further- more concrete statements are made in these directives concerning the scope and profundity of the training of these specialists and the responsibilities for this training.

Because in the event of a chemical accident the local fire brigade is almost invariably the first intervention unit to arrive on the scene, a 'Handout for the Behavior of Local Fire Brigades in Case of Chemical Accidents' [4] was created in order to help local fire brigades to take the right immediate measures without disregarding their own safety. In June 1985 the SFFA organized a conference for the authorities of the cantons responsible for chemical defence and informed them about the chemical defence concept and the directives and handouts concerning chemical defence. The president of the central committee and the chemical consultant of the SFFA asked the representatives of the cantons to translate the chemical defence concept into action in order to realize an efficient chemical defence organization in the whole of Switzerland. Even after this conference several cantons were still not convinced of the chemical risks existing on their territory and the necessity to develop an efficient chemical defence organization. As a result the president of the central committee and the chemical consultant visited the responsible authorities of these cantons and tried to persuade them in a personal discussion to create the necessary structures for an efficient chemical defence organization. But even these efforts proved unsuccessful - after all this was the period before the fire of Schweizerhalle!

\section{The Chemical Fire of Schweizer- halle and its Consequences}

The date of the 1 November 1986 is a deep rift in the history of the chemical industry, not only in Switzerland, but also in the rest of Europe. The population had hardly recovered from the shock of the nuclear power plant disaster at Tschernobyl in the Ukraine with radioactive contamination of large parts of Europe on 26 April 1986, when a new disaster happened in the night of 1 November 1986. As the result of a major fire in a warehouse containing agrochemicals, tens of thousands of people in the nearby city of Basel were woken up terrified in the middle of the night by the wail of the sirens and extremely strong smells which caused a true disturbance. As large volumes of heavily contaminated water from the fire extinguishers entered the river Rhine directly from the site of the fire, a catastrophic number of dead fish was observed the following day. Hundreds of tons of dead eels and fishes drifted down river towards the sea. The river Rhine was temporarily biologically dead for long stretches. Even at a distance of several hundreds of kilometers from the fire drinking water supplies taking water from the Rhine had to be shut down for safety reasons. In many countries all over Europe - but especially in Switzerland - the confidence in the chemical industry was severely shaken. But the disastrous fire of Schweizerhalle, the cause of which - in spite of extensive investigations - has never been discovered, prompted the political authorities to take action. In analogy to the 'Council Directive 96/EC of 9 December 1996 on the Control of Major-Accident Hazards Involving Dangerous Substances' [5] (Seveso-Guideline of the European Union), in Switzerland the 'Ordinance of 27 February 1991 on Protection against Major Accidents' (Ordinance on Major Accidents [1]) - based on article 10 of the 'Federal Law of 7 October 1983 Relating to the Protection of the Environment' [6] - was drafted in an exceptionally short time. At the same time the European Union tightened up the Seveso-Guideline.

Beyond that the fire of Schweizerhalle had far-reaching consequences for the chemical defence forces, the intervention planning of the fire brigades and the precaution measures in the field of retention of extinguishing water. After Schweizerhalle new chemical defence bases were set up and existing bases in Switzerland were reinforced. Even cantons which hitherto had staunchly resisted the acknowledgement of the chemical risks existing on their territory, began to develop chemical defence organizations. The Federal Environment Office subsidized these developments with investment contributions. The 'Ordinance on Major Accidents (OMA)' requires high chemical risk enterprises to agree an intervention plan with the public intervention forces and obliges the cantons to coordinate the intervention planning. Therefore the authorities of the cantons responsible for the execution of the 'OMA' began to elaborate the intervention plans together with the enterprises in question and the chemical defence bases. The 'OMA' obliges all the enterprises subjected to the ordinance to submit a short report to the authority of the canton wherein the hazardous materials stored and the measures already taken to prevent major accidents are listed. If the short report cannot exclude serious risk to the population or the environment in the event of a major accident, the canton has to oblige the enterprise to do a detailed risk analysis. Such risk analyses show quite often that the risk for serious harm to the population or the environment can only be reduced to a tolerable extent if the amounts of hazardous materials are limited or basins to retain dangerous liquids and contaminated extinguishing water are built. Since the 'OMA' came into force on 1 April 1991 hundreds of millions of Swiss Francs have 
been invested in the construction of such basins.

\section{Chemical Defence within the Bounds of the Protection of the Population}

In view of the planned new army reorganization (Army XXI) and the complete restructuring of the civil protection to the population protection on 13 February 1998 , the Conference of Governments of the Cantons for the Coordination of Fire-Fighting (CGCFF) appointed an 11-membered group of experts in order to develop a forwardlooking concept for the organization of firefighting in Switzerland. The group of experts developed the concept in the form of 22 principles named 'Fire-Fighting 2000 plus' [7] at the end of 1998, so that it could be adopted by the plenary meeting of the CGCFF on 12 February 1999.

These principles emphasize among other items that

- rescue, fire-fighting and damage prevention as an overall concept are the tasks of the fire brigades (principle 5);

- local, regional and professional fire brigades should have a modular structure and special equipment should be provided regionally (principle 8);

- in the event of a disaster the civilian authorities have to rely on support by the army. As in case of big disasters in peacetime for the short term mostly only military equipment without troops is needed, the military authorities should take the steps to supply the civilian authorities with the equipment needed (principle 20).

These principles clearly show that within the bounds of population protection, chemical defence - belonging to the intervention forces which have to be provided regionally according to principle 8 - is of great importance. The special army equipment needed by the civilian authorities in the event of a chemical disaster can be found in the corps equipment of the 'Disaster Control Regiment 1' in the containers number 2 (Chemical Defence/Radioprotection) and number 8 (Environment Protection).

\section{Training of the Specialists for Chemical Defence}

The fire-fighting organization in Switzerland designates the training of instructors of all fields to the SFFA whereas the cantons are responsible for the remainder of the training. After the 'Directives for Chemical Defence for Fire Brigades/Directives for the Training of Chemical Defence Specialists' [3] came in- to effect in 1985 the training of the chemical defence specialists should have been organized and carried out by the responsible authorities of the cantons. Because most cantons did not have the necessary knowhow and specialist staff to carry out the chemical defence training courses, the SFFA decided to take direct control of the whole chemical defence training as long as the cantons did not have enough trained chemical defence specialists and officers at their disposal. In the years from 1986 till 1992 the SFFA organized and carried out six basic courses for chemical defence specialists and officers. After this period it was assumed that most of the chemical defence bases of the cantons had enough chemical defence specialists and officers at their disposal to guarantee efficient and safe intervention and adequate training. In 1993 the SFFA did not carry out any chemical defence training courses, but made the necessary preparations to realize the new chemical defence training concept, namely the training of officers-in-charge for chemical accidents and of instructors for chemical defence. In the following year the first training courses based on the new concept were carried out: a course for officers-incharge for chemical accidents in Rorschach and a course for instructors for chemical defence in Vernier near Geneva. Since that time the new division of the responsibility for training in the field of chemical defence - training of officers-in-charge and of instructors by the SFFA and basic training of specialists and officers by the cantons and the chemical industry - has proven worthwhile.

\section{Tasks and Responsibilities of the Chemical Defence Intervention Forces}

Every chemical defence base should be able to deal independently with chemical accidents in its area of action. In order to establish the optimal - not maximal! - necessary equipment and personnel of a chemical defence base as well as the needs for training, it is essential that corresponding scenarios are developed. Starting from these scenarios the corresponding plans of action have to be drafted. It cannot be excluded - unless this has been done before that these scenarios are the cause and starting point for additional safety measures in the field of prevention of major accidents. The plans of action of stationary plants dealing with hazardous materials have to be worked out together with the owner of the plant and to be periodically checked by an exercise.

According to the revised 'Directives for the Chemical Defence for Fire Brigades' ([8], edition 1997) of the SFFA the inter- vention forces for chemical defence have beside others - the following tasks:

- to recognize and avert immediate dangers, protect human beings from dangers or to evacuate them from the danger zone and protect themselves from the effects of chemical substances;

- to minimize as far as possible the effects of chemical accidents on the environment (ground, water, air);

- to preserve material assets and prevent damage as far as the actual situation of danger allows this;

- to elaborate plans of action for objects endangered by hazardous materials;

- to proceed in a tactically correct way in the event of a chemical accident to reduce the dangers for the intervention forces and uninvolved persons to a minimum;

- to reduce the chemical risks after an accident to a degree that specialists are able to start the rehabilitation measures on the site.

\section{Identification of Hazards}

A rapid and complete identification of the existing hazards is the most important point of every intervention after a chemical accident, i.e. the knowledge of all hazardous materials involved in the event and of their effects on human beings and the environment.

An important aid for the identification of hazards are the orange plates with UNand danger numbers, the danger labels, the $\mathrm{R}$ - and $\mathrm{S}$-sentences and for transport, the written instructions on the vehicle.

In order to take the correct measures immediately the intervention forces have at their disposal beside other aids: 'ERICards' [9] with the additional Swiss file on 'Oil, Chemical and Radiation Defence' [10], the chemical databank IGS and the safety data sheets (Fig. 1).

\section{Standard Operation Procedures}

It has already been explained in section 6 that in order to establish the necessary equipment and personnel of a chemical defence base the development of the corresponding scenarios for chemical accidents is absolutely essential. Furthermore it has been said that on the basis of these scenarios plans of action have to be drafted.

In order to deal in a rapid and efficient way with a chemical accident without disregarding their own safety it is advisable for the intervention forces to work out certain standard operation procedures and to check them in exercises. Possible standard operation procedures are for instance: 


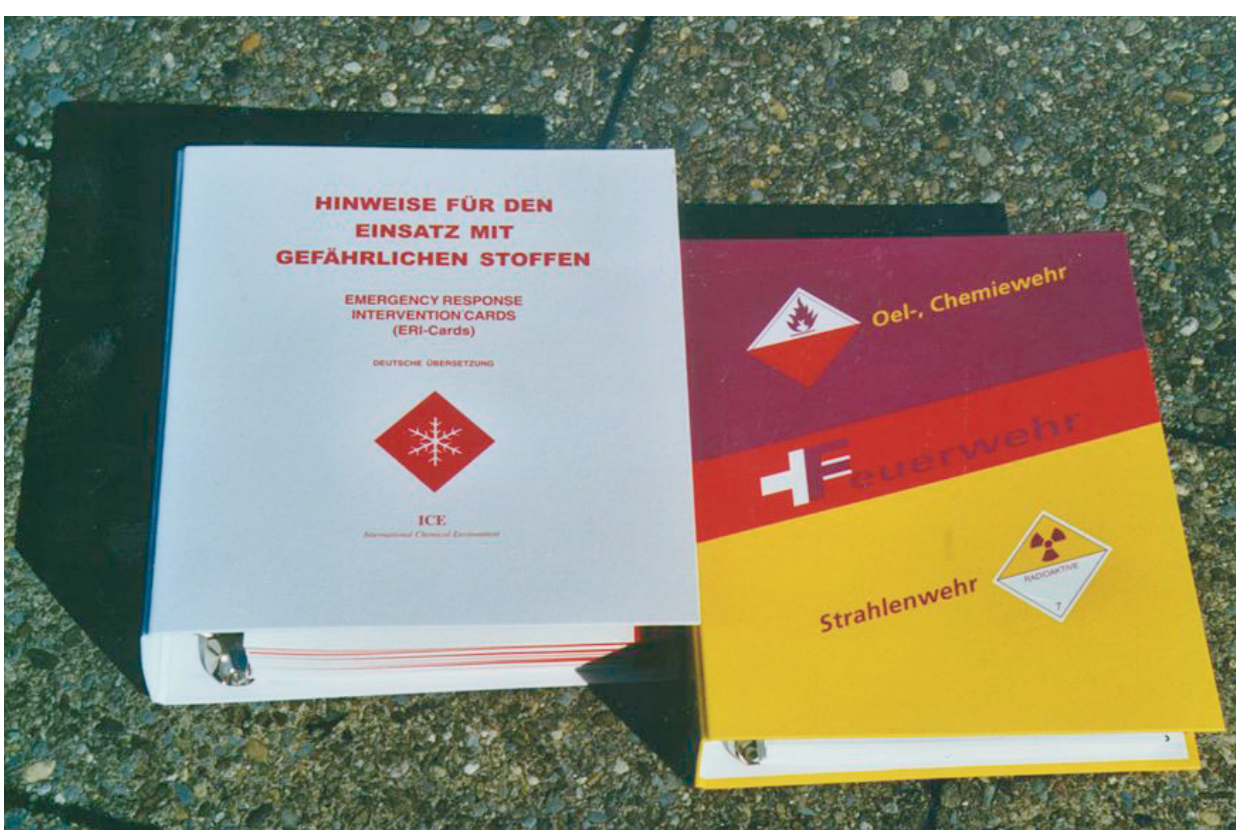

Fig. 1. 'ERI-Cards' and the Swiss file 'Oil, Chemical and Radiation Defence' are valuable tools to define correct measures of the intervention forces

- Condensing/washing out of gases and vapors after an outbreak of toxic, corrosive or inflammable gases which have a higher or the same density as air (Fig. 2);

- Sealing leaky tanks or other containers filled with corrosive, toxic, inflammable liquids or liquids harmful to the environment as well as pumping such liquids from the leaky tanks or containers to reserve tanks with the necessary precautions to prevent dangerous electrostatic charging;
- Containment of chemical spillages and contaminated extinguishing water (Fig. 3);

- Fighting gas fires;

- Decontamination of persons affected by hazardous materials.

In accordance with the plans of action additional standard operation procedures may be elaborated. The more frequently such standard operation procedures are practiced the more successful and smoothly the intervention will proceed in the event of an emergency.

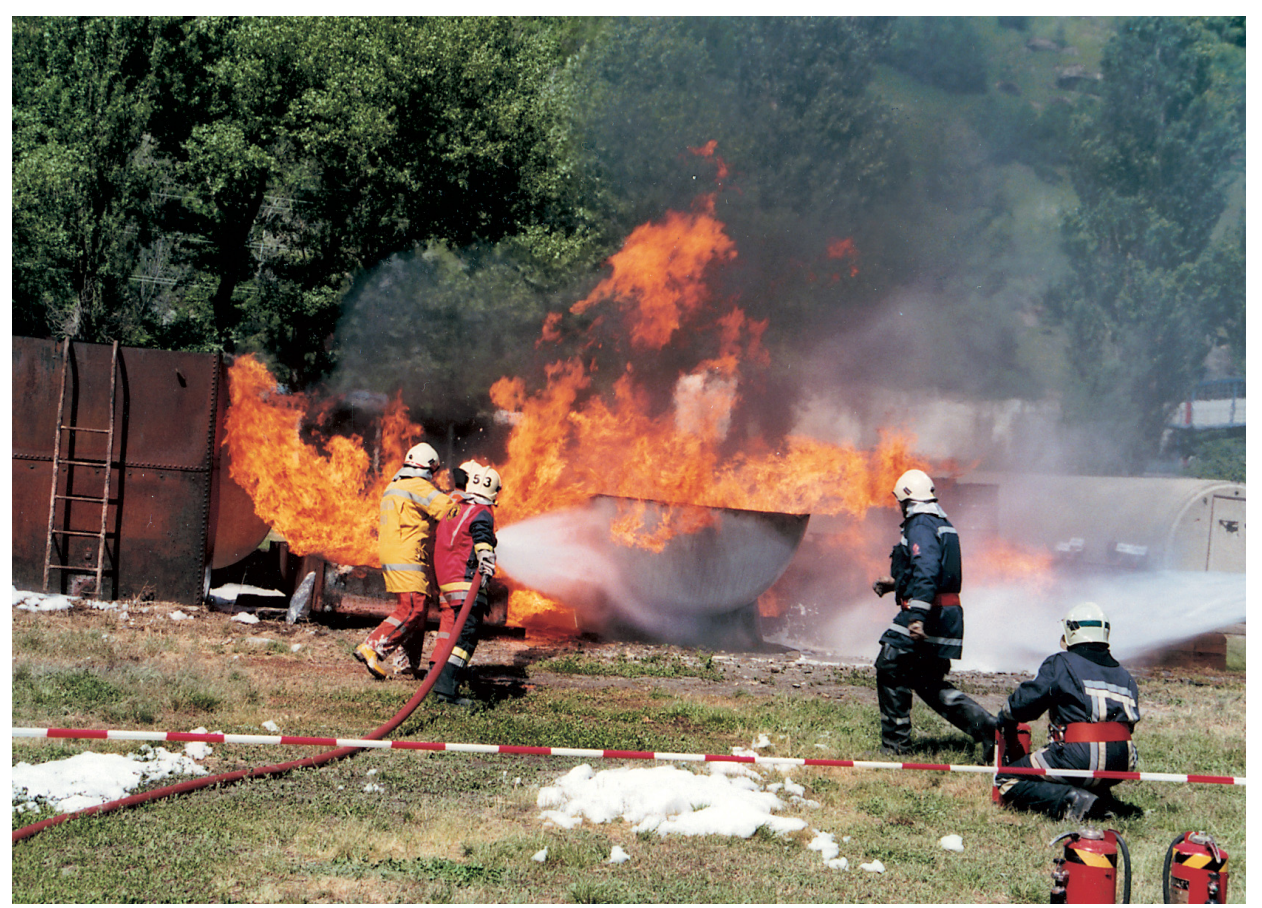

Fig. 2. 'Hot exercise' of fire fighters with the goal of cooling a hydrocarbon fire

\section{Emergency Documents and Pocket Guides for Chemical Defence Interventions}

Parallel to the rapid development of the chemical industry in the sixties and seventies of the past century the transport of hazardous goods on road and rail increased enormously. Several transport accidents involving hazardous materials showed very rapidly that the fire brigades did not have the necessary equipment, protective clothes and knowledge at their disposal to deal successfully with this new form of threat. Furthermore no written instructions and guidebooks on efficient and safe action in case of an accident with hazardous materials were available at that time.

In that situation the former chief of the fire brigade of the chemical company LONZA AG in Visp, Rudolf Sandmeier, and the former chief of the professional fire brigade of Bern, Hans Bürgi, decided to create together with Dr. Michael Gut, responsible for the transport of dangerous goods at the Swiss Society of Chemical Industries, a guidebook which should enable the fire brigades to intervene after accidents with the involvement of hazardous materials in a safe and efficient way. The result of the work of the three pioneers was a file in A4 format, containing tactical and technical instructions for chemical accidents as well as useful information and charts. Furthermore the file contained for every UN-Number a leaflet with the most important properties and dangers as well as instructions on how to deal with the substance and the protective equipment and extinguishing agent to be used. The file with a red cover commonly named the 'Red File' was published under the name 'Intervention Documents for the Transport of Dangerous Goods' jointly by the Swiss Society of Chemical Industries, the Federal Office for Police and the SFFA which later was also responsible for the sale of the file. As the number of hazardous materials classified by an UN-number and therefore also the number of data sheets in the 'Red File' increased dramatically at the end of the 1970s the documentation system was changed from substance to group data sheets. Instead of creating one data sheet for every substance several substances with similar properties are united in a group, and the information concerning dangers, protective clothing, intervention instructions and so on are given with standardized phrasing on one group data sheet. The information given on a group data sheet corresponds to the most dangerous substance of the group. Instead of far more than 1000 substance data sheets - filling beside the existing file two more files - the 'Red File' contained roughly 180 group data sheets. In the mid-1990s the department of road traffic was reassigned on the occa- 


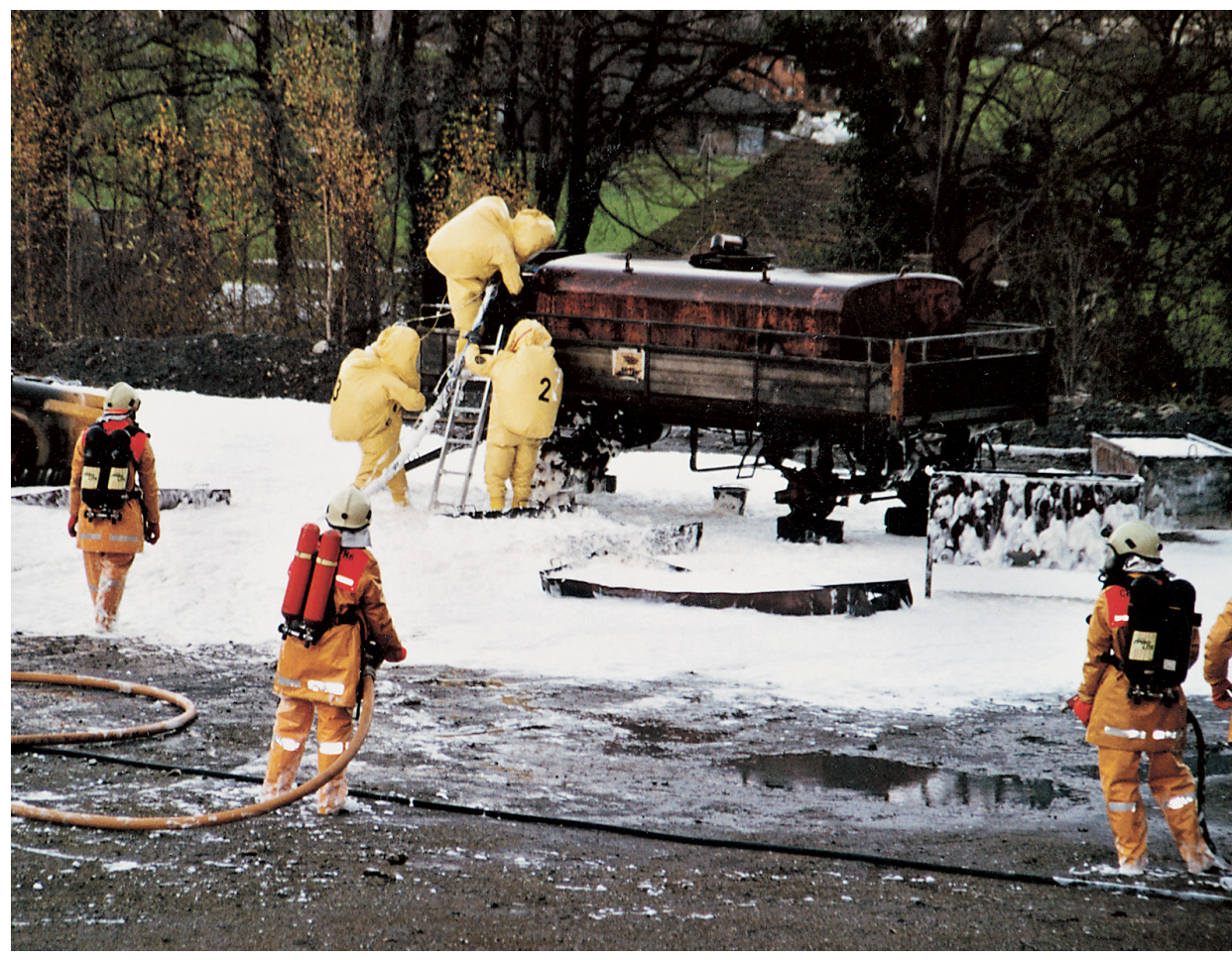

sion of the reorganization of the federal administration from the Federal Office for Police to the Federal Office for Roads. As a consequence the federal administration began to withdraw step by step from the update and publication of the 'Red File', named now 'File for Intervention after Chemical and Radiological Incidents'. In July 1999 finally the Federal Office for Roads wrote a letter to the affected authorities and partners informing them about the immediate withdrawal from the cooperation concerning the 'Red File'. The affected fire fighting authorities therefore decided to replace the 'Red File' by 'ERI-Cards' (Emergency Response Intervention-Cards) which have been drafted by the European Association of Chemical Industries (CEFIC). These 'ERI-Cards' correspond closely to the group data sheets of the 'Red File'. As the 'Red File' not only contained the group data sheets but also quite a number of other important intervention documents, these documents were united, updated, completed and published in the additional file 'Oil, Chemical and Radiation Defence' [10] supplementing the information given by the 'ERI-Cards' [9]. The 'ERI-Cards' and the additional file 'Oil, Chemical and Radiological Defence' were given to the intervention forces during 2002.

As it was realized at an early stage that in most cases local fire brigades arrive first on the site after a chemical accident, in 1985 the 'Handout for the Behavior of Local Fire Brigades in Case of Chemical Accidents' [4] was created in addition to the 'Directives for Chemical Defence for Fire Brigades/Directives for the Training of
Chemical Defence Specialists' [3]. This handout was revised in 1990 and 1999 and adapted to new legal regulations and new findings gained from accidents and proved its worth in the practical training as well as in emergencies.

In 1996 the 'Directives for Chemical Defence for Fire Brigades/Directives for the Training of Chemical Defence Specialists' [3] was completely revised, united and published 1997 under the title 'Directives for Chemical Defence for Fire Brigades' [8].

Further documents and handouts for interventions after chemical accidents are the 'Handout for the Decontamination after Chemical Accidents' [11], published 1999, and the 'Handout for Fire Fighting Interventions in Tunnels' [12], published 2000. Still in discussion in the Committee for Chemical Defence of the SFFA is the elaboration of a 'Handbook for Chemical Defence'. The objective of this Handbook would be to combine and unite all the basic knowledge, findings and principles for interventions which are of importance for the training as well as emergencies.

Received: November 19, 2003

[1] 'Protection against Major Accidents (Ordinance on Major Accidents, OMA)', SR 814.012, Feb. 27, 1991.

[2] 'Concept Coordinated AC-Protection', Jan. 24, 1990.

[3] 'Directives for the Chemical Defence for Fire Brigades/Directives for the Training of Chemical Defence Specialist', SFFA, 1985.
Fig. 3. When the explosion hazard is contained by a foam layer, chemical defence specialists start their job of sealing containers containing hazardous materials
[4] 'Handout for the Behavior of Local Fire Brigades in Case of Chemical Accidents', SFFA, 1999.

[5] Council Directive 96/82 EC, 'Control of Major-Accident Hazards Involving Dangerous Substances (Seveso-Guideline of the European Union)', Dec. 9, 1996.

[6] Federal law, 'Protection of the Environment (LPE)', SR 814.01, Oct. 7, 1983.

[7] 'Fire-Fighting 2000 plus', Conference of Governments of the Cantons for the Coordination of Fire-Fighting, Feb. 12, 1999.

[8] 'Directives for the Chemical Defence for Fire Brigades', SFFA, 1997.

[9] 'Emergency Response Intervention Cards (ERI-Cards)', CEFIC, Brussels, 2000.

[10] 'Oil, Chemical and Radiation Defence', Gebäudeversicherung Kanton Zürich, 2002.

[11] 'Handout for Decontamination after Chemical Accidents', SFFA, 1999.

[12] 'Handout for Fire Fighting Interventions in Tunnels', SFFA, 2000 